\title{
An aircraft as a museum object
}

\author{
HANNU VALTONEN*
}

\begin{abstract}
Complicated technical museum objects differs greatly from traditional museum objects. This article tests both the museological concepts of authenticity and originality and the concepts of conceptual, factual and actual identity with two aircraft in the collections of the Aviation Museum of Central Finland. The main issue is how these concepts may help to solve some problems of conservation, restoration and presentation. This article is an translated and slightly edited excerpt of the PhD thesis "Tavallisesta kuriositeetiksi - Kabden Keski-Suomen Ilmailumuseon Messerschmitt Bf 109 - lentokoneen museoarvo (From Commonplace to Curiosity - the Museum Value of two Messerschmitt Bf 109 Aircraft of the Aviation Museum of Central Finland"), examined in the University of Jyväskylä, Finland, on March 24, 2006.
\end{abstract}

Keywords: Aircraft, authenticity, originality, conceptual identity, factual identity, actual identity, conservation, restoration.

\section{THE LIFESPAN OF A MUSEUM OBJECT}

Peter van Mensch's theory of the object data structure is based on the concept of lifespan, and involves the reduction, disappearance, or even increase with the passing of the time, of the original value of an object. Secondary uses also play their part. This thesis, in which the focus is on military aircraft, deals with an object whose primary function is to fly, be an airplane, and deliver weapons if required, while its existence as a static display item or museum exhibit constitutes its secondary function. During the lifespan of an object its informational value undergoes changes and can be divided into four categories. An object's structural properties encompass its physical nature. Functional properties are examined against future or current usages, while background (context) involves the physical and conceptual environment of the object, and significance (representation) is assessed on the basis of the meanings and values conveyed by the object. ${ }^{1}$ The basic unit of a museum collection is an item (object), and a collection is formed by objects. This leads us to the eternal quest of the definition of an object and of the ways of determining its value - and what about the importance of an object as a piece of material evidence or source of information? What is the relationship of a museum or man with an object? These questions must be answered using solid museological arguments before it can be determined that an item meets the criteria of a museum object. Age alone will not qualify as a criterion. Objects convey information of the past so their inherent connections with history lend them credibility as pieces of 
material evidence. In addition to their physical characteristics, objects have documentary nature. An object's importance may lie in the power of expression that it carries or in its metaphysical characteristics. Objects are invariably tangible pieces of material evidence, even though we may fail to recognize their value. They are without exception representative products of their own culture, and every object possesses a specific meaning and significance that can be assessed against the overall picture of the culture of which they were part. ${ }^{2}$

Peter van Mensch classifies objects as temporary, or short-lived, and permanent. To determine the informational value of an object it is necessary to learn the process of transformation undergone by the object. Van Mensch's model of the informational structure of an object is built around three levels of information: physical characteristics, documentation, and background information (context), which may result in a situation where the underlying basic, or original, information that an object carries may differ completely from secondary information that is available for us to view. Museums have far too long focused on objects' physical characteristics and associated documentation, while contextual information including stories and reminiscences related to objects have been ignored. ${ }^{3}$

Susan Pearce has fittingly stated: "The relationship of our museum material to the ways in which we view the past and produce our narratives of what happened in the past, is both one of the most important and one of the most difficult question which museum collections pose." Pearce is known, among other theories, for her four field approach ${ }^{5}$, which, however, cannot be applied as such to aircraft as we cannot refer to a flying machine as a "masterpiece", and to me the idea of the wanderings of an object between "high culture" and "popular culture" sounds strange when reference is made to the characteristcs of a technical apparatus such as an aircraft.

The correct context of an object, which we should strive to determine, includes its conceptual identity ("basis of design", based on an idea), factual identity (the object is "ready for use" with regard to its structure, functionality, and intended purpose), and actual identity (the object in its "present state", and associated history). ${ }^{6}$

\section{MESSERSCHMITT BF 109 AIRCRAFT AS MU- SEUM ITEMS}

The Messerscmitts of the Aviation Museum of Central Finland are German fighter aircraft. Finland purchased 164 examples of the Bf $109 \mathrm{G}$ aircraft from Germany, and 112 of these were of the G-6 sub-type. Their service life in Finland lasted eleven years to the day, the last flight being flown on March 13, 1954, by MT-507 (Finnish Air Force serial number), which is on display in the museum. After its farewell flight the aircraft was a gate guardian at an air base for seventeen years. It was restored in 1972 and was stored pending the establishment of an aviation museum. The museum's second aircraft, a Bf 109 F-4 (Luftwaffe serial NE+ML), got lost and force-landed on a ferry flight in the northernmost part of Finnish Lapland on November 9, 1942. The wreckage was severely vandalized, and many parts were lost until the remains were recovered from the wilderness as late as 1972 . The aircraft was only subjected to preliminary conservation ten years later when it was taken into the museum's collection. 
The story of an object starts with its conceptual identity and progresses via a factual identity to an actual identity. MT-507, a Messerschmitt Bf 109 G-6 fighter, is a representative of the best fighter type that was available to Finland and the best the country was in the position to purchase from anywhere in the world during the latter stages of World War II in the closing weeks of the summer of 1944. It then very quickly became obsolescent as a military aircraft, even spending some time mothballed in storage. Its value as a machine of war dropped and the aircraft was in the descending portion of its life span. When MT-507 was removed from storage and restored into service in 1949, the Messerschmitt Bf 109 G was already hopelessly outdated as a military aircraft as widespread transition to jet aircraft had taken - or was taking - place elsewhere. Technically, MT-507 was a sound airplane, not a "Monday product", so it remained airworthy longer than any other aircraft of its type, but the final flight inevitably had to take place. After this, the aircraft began its spell as a gate guardian; this period, a sort of a pre-museal phase in its life, was a sad one as the aircraft was incessantly ravaged by elements, but subsequent restoration resulted in an increase in its value, which peaked in the aircraft's placement in the permanent exhibition of the Aviation Museum of Central Finland.

What is the conceptual identity of MT507? Is it the performance specification drafted by the Air Ministry of the Third Reich (Reichsluftfahrtministerium, RLM), the first flight of the Bf $109 \mathrm{~V} 1$ prototype on 28 May, 1935, or the maiden flight of the Bf 109 G-0, which was the first pre-production "Gustav"? Hermann Göring's announcement that a "very fast courier airplane" was required does certainly not qualify as the conceptual identi-

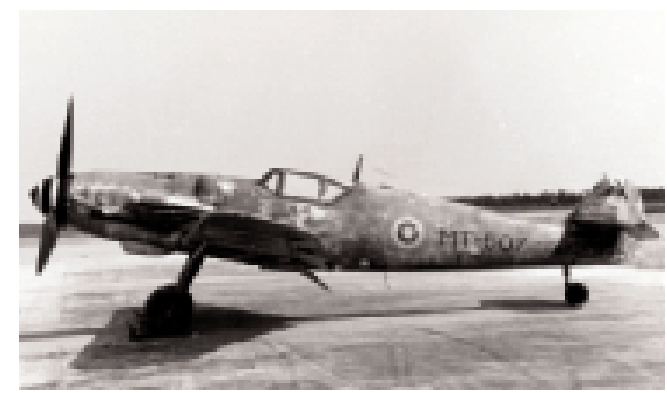

Fig, 1. Messerschmitt Bf 109 G-6, MT-507, has been taken into service in late summer 1949 at Finnish Air Force 31st Fighter Squadron after a long storage period and is thus practically factory-new. Photo Aviation Museum of Central Finland.

ty of this complex and sophisticated piece of machinery. Would the final performance requirements that the Air Ministry laid down for the aircraft qualify, then? They may not be specific enough and therefore cannot qualify either. What about the drawings of the first prototype? Yes, they could indeed be considered; however, it is certain that late changes were incorporated in the aircraft during its manufacture. ${ }^{7}$ A number of design changes were also made between the first prototype and Bf 109 A-1, the first production version. The emergence of the Bf $109 \mathrm{E}$ version also represents a major step; in fact, the Germans maintained that the design did not achieve maturity as a serial production aircraft until the advent of "Emil". Even bigger changes were made as the aircraft was further developed into the Bf 109 F, known as "Filip". These included the redesign of the wings, which resulted in an aircraft that aerodynamically differed considerably from its predecessors. The differences between "Emil" and "Filip" were, in fact, of such a major nature that the building up of manufacturing capability and initial technical problems caused the loss of almost 
100600 production aircraft, which means that a gap of 2.5 months appeared in Germany's aircraft production. ${ }^{8}$ Transition from the Bf 109 F to the Bf 109 G, or "Gustav", was, however, smoother.' Enter "Gustav": it had approximately three times more power and it weighed about twice as much as the Bf $109 \mathrm{~V} 1$ and first serial production aircraft, and major external differences are also readily apparent, whereas Bf 109 F-4 NE+ML and Bf 109 G-6 MT-507 resemble each other markedly. I therefore maintain that MT-507 and the entire G series are preceded by a full range of conceptual identities.

It may prove equally difficult to determine the conceptual identity of the final serial production examples of the British Supermarine Spitfire fighter. An initial order for the type was placed in January 1935, the first prototype flew on 5 March, 1936, and production terminated in October 1947. The case of the Volkswagen "Beetle", which was still in production a few years ago, is also a like example. The car was ordered in 1934, and by the winter of 1936 Ferdinand Porsche had built three prototypes. These were followed by an order for a further 30 prototypes in 1937. Production started just before the outbreak of the war, but it ended soon, the factory switching from family cars to the production of VW Kübelwagen and Schwimmwagen all-terrain vehicles. How much does a "Beetle" out of a production line that was closed in Brazil a couple of years ago resemble the first production automobiles - not that much. ${ }^{10}$

The case of the Bf $109 \mathrm{~F}-4$ resembles the foregoing so the F series is one link in the chain of the conceptual and factual identities of Messerschmitts before the arrival of "Gustav". ${ }^{11}$

In my opinion, the factual identities of the Messerschmitts that are the subject of this stu-

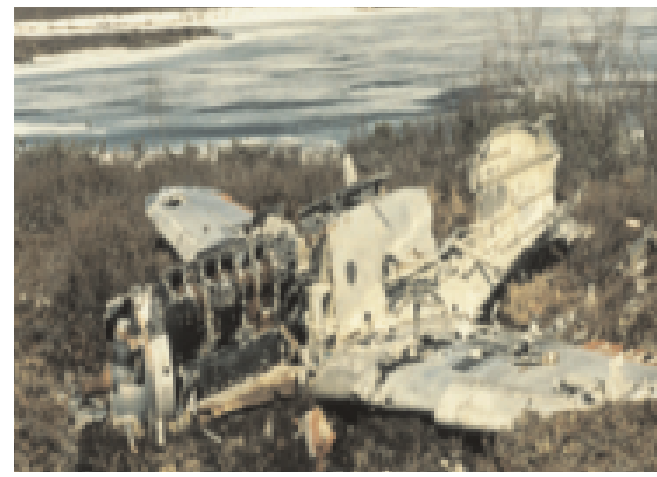

Fig. 2. Messerschmitt Bf 109 F-4, Luftwaffe NE+ML, at the shore of Lake Tsiegalasjärvi at the beginning of June 1972 before transportation to the Finnish Airforce Depot and later (1978) to the Aviation Museum of Central Finland. Photo Hannu Valtonen.

dy are, however, relatively easy to determine, as these identities were born when the aircraft were put at the manufacturer's plant through their acceptance test flights that cleared them for handover to service units. By early December 1943, German aircraft industry had established the following manufacturing standards for aircraft:

- "Saur-fertig" (Saur ready): the standard for an aircraft that had undergone a manufacturing process (at the factory); yet the aircraft lacked some small components that would be installed later but would be needed to render it airworthy,

- "Industrie-fertig" (factory ready): an aircraft was raised to this standard upon the installation of components mentioned above,

- "Gl-fertig" (Generalluftzeugmeister-fertig, Director of Aircraft Production ready): an aircraft reached this standard with the installation of the armament, and

- "Übernahmefertig" (acceptance ready): an aircraft met the criteria for this standard af- 
ter the completion of weapons firing tests and production test flights. ${ }^{12}$

With reference to the foregoing definitions of manufacturing standards it can be maintained that MT-507's factual identity was born when the aircraft was proved acceptance ready (übernahmefertig) around July 27, 1944, while the respective date for $\mathrm{NE}+\mathrm{ML}$ is somewhere near June 21, 1941. What has been said above is, of course, not at all applicable in modern aircraft industry, and has bearing solely to Nazi Germany's war effort.

\section{AN AUTHENTIC OBJECT}

As early as 1858, J. G. Droysen advised that the very first thing to do was to make sure that an object is not a forgery. "To put it briefly, there are so many things around that are not authentic and are therefore a forgery that every time that one is dealing with history he shall first ensure that the material he has in his hands is what it is believed to be or what it should be."13 Could this statement be understood that some exceedingly weird items had found their way into the collections of the high and mighty?

How can one possibly define the concept of "authenticity" when the object in question is an item like an airplane, which during its service life is inherently subjected to successive repairs and modifications? What criteria should be used in the selection of a certain point of time in the aircraft's lifespan that would determine the appearance of the aircraft after repainting, for example? Or what technical configuration should be used for reference? To take MT-507 as an example, even the aircraft's acceptance documents list the following major deficiencies that had to be actioned immediately, before the aircraft could be handed over to an operating unit:

- radio is missing,

- instruments are attached with two screws (instead of four!)

- all connections of oil and fluid plumbing above size NW 20 lack safetying,

- no elongation observed in $32 \mathrm{~mm}$ eye-bolts of stabilizer,

- tropical filter with attaching parts and controls is missing,

- air intake duct reinforcement is missing,

- supports of receptacles of upper engine cowling latches are not reinforced,

- engine preoiling line is missing,

- some high-pressure lines are faulty,

- Finnish serial number, national insignia, and other markings must be applied, and

- Finnish language placards must be installed.

Aircraft documents state that the aircraft was 96\% complete upon acceptance due to these deficiencies, while the record of release and acceptance mentions additional minor discrepancies. Some of the foregoing deficiencies result from attempts to relieve workload on factory assembly lines by assigning certain steps (such as the installation of remaining attachment screws of instruments and safetying of larger-diameter oil and fluid pipes) to central depots (Flugzeugschleuse) or operating units, while others can be traced to the policy of exhausting the stocks of components supplied by sub-contractors (the "incorrect" high-pressure oil lines and the stabilizer eye-bolt were of an obsolete type), and still others were due to the unavailability of components or the fact that their installation would have served no practical purpose. An example was the radio; 


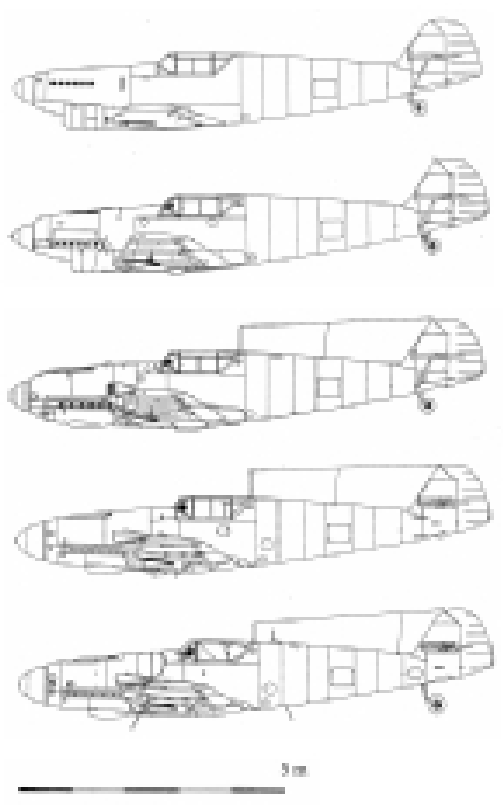

Fig. 3. The prototype and some versions of Messerschmitt Bf 109 from top to bottom: V1, A-1, E-1, F-1 $(N E+M L)$ and $G-6$ (MT-507). Drawings by Klaus Niska.

it can be assumed that radios were in short supply, yet radio sets could be pulled out of grounded aircraft in operating units. MT-507 was also fitted with attachment straps for a first aid kit, the fuel filler door was repaired, wheel brakes were worked on (after Finnish Chief Warrant Officer Yrjö Turkka had reported a malfunctioning left brake unit), and the guns were harmonized and test-fired. ${ }^{14}$

After the armistice, which became effective on September 5, 1944, the Eastern Front markings were painted over, and the current roundel replaced the swastika as the national insignia on April 1, 1945. Operations from dirt airstrips resulted in frequent hits by small rocks against the aft fuselage and rudder, ma- king skin repairs and local repainting necessary. For tactical purposes MT-507 wore, apparently from early September 1944 onward, a yellow "0" behind the machine gun breech bulges on the forward fuselage, but during major part of the aircraft's operational life between 1949 and 1954 this was replaced by a yellow " 4 " on the vertical stabilizer. ${ }^{15}$ Nitrocellulose paint applied on the aircraft gradually lost its properties, revealing underlying surfaces, so paintwork was touched up as necessary.

On the basis of the facts presented above it can be stated that the the date on which MT507 arrived in its assigned operating unit and received its "zero" (tenth aircraft of the flight?), i.e., September 4, 1944, is of significance in the history of the aircraft, and when the painting of the aircraft was discussed I strived to have it painted in the "original" colors it wore on that day. It must be admitted, however, that even the most meticulous restorer would have failed in his attempts to restore the aircraft to its then existing exact technical standard with its high-pressure oil lines, eye-bolts, and other parts of an "incorrect" type. As for painting, "cutting corners" must also be accepted, as rudimentary spraying equipment that were used in the bygone days may no longer be available, and the same applies to the availability of original paints. Is this perhaps one reason for the almost invariable failure of the mottled Luftwaffe camouflage applied on museum aircraft all over the world to convey an impression of authenticity?

Cannibalizing, which means temporary removal or changing of parts and components between individual aircraft, is not inseparated from the issue of authenticity. This practice became inevitable due to maintenance difficulties of the Messerschmitt fleet. Let us take MT-452 as an example: 


\begin{tabular}{|c|c|c|}
\hline Date & Removed from & Component installed in MT- 452 \\
\hline Aug 12, 1947 & MT-483 & left and right mainwheel and tire assembly \\
\hline Aug 13, 1947 & MT-481 & propeller spinner \\
\hline Aug 14, 1947 & MT-481 & vertical speed indicator \\
\hline Jan 31, 1948 & MT-438 & horizontal stabilizer and elevator \\
\hline Jun 8, 1948 & MT-490 & right mainwheel tire \\
\hline Jun 16,1948 & MT-504 & engine complete with mounts and accessories \\
\hline Jun 16,1948 & MT-504 & propeller \\
\hline Jul 27, 1948 & MT-456 & gun empty case collector box cover \\
\hline Sep 22, 1948 & MT-425 & engine complete with mounts and accessories \\
\hline Sep 22, 1948 & MT-425 & propeller \\
\hline Oct 2, 1948 & MT-513 & cockpit canopy complete with antenna \\
\hline Oct 29, 1948 & MT-513 & fuel boost pump \\
\hline Dec 28, 1948 & MT-438 & oil cooler \\
\hline Dec 29, 1948 & MT-425 & left radiator \\
\hline Jan 8, 1949 & MT-422 & fuel quantity gaging system float \\
\hline Feb 14, 1949 & MT-513 & tailwheel \\
\hline Apr 27, 1949 & MT-513 & left main landing gear oleo \\
\hline Aug 14, 1949 & MT-509 & right wing \\
\hline
\end{tabular}

The list includes only those repairs or component changes that were carried out by cannibalizing, which is indicative of the scarcity of spares, and it does not include other repairs or installation of stock spares. During its life span the airframe of MT-452 logged a total of 311 hours 45 minutes, and was fitted with five individual engines and eight propellers. Replacement or reconditioning of components and equipment are an inherent part of aircraft operation, these being carried out when it becomes necessary to replace a faulty component with a serviceable one, either after a predetermined number of flight or running hours has elapsed, or during repairs. ${ }^{16}$
OVERHAUL OF AN AIRCRAFT - AN AUTHENTIC EVENT

Let us, for comparison, examine the record of repairs to the airframe of a De Havilland D.H.60 Moth (Finnish registration OH-VKG, named "Hallin Janne") that were undertaken at the Karhumäki Brothers' shop in Keljo, Jyväskylä, between April 5 and August 14, 1940. The Moth was widely used in the 1930s and was of wooden construction. Repairs included the complete replacement of wooden components (this writer's italics and underlining). Metal parts that were replaced included the lower wing attachment brackets complete 
with lock pins, along with the corresponding internal brackets. The attaching hardware of the rear struts of the float assemblies, attachment brackets of the center wing panel, attachment bracket of the forward bracing wires of the center wing, attachment brackets of stabilizer struts, engine mounting brackets, and the access door latch were replaced. All other metal components were reinstalled after cleaning and inspection. Seats complete with seat back, as well as the windshield assemblies including frames were replaced. Seat harnesses were repaired. The instrument panel was replaced. Mounting bolts used in the fuselage structure complete with washers were replaced. The inside of the fuselage was varnished and external paint was applied. Cowlings were replaced. ${ }^{17}$

How much of "genuinely original" then remains in a wooden aircraft after an overhaul? Authenticity can, however, be maintained even after component changes and the replacement of structural members providing replacements and modifications are an inherent part of the service life of an item before its becoming a museum object. This phenomenon is also recognized elsewhere, its most striking example probably being the Shinto shrine in Ise, Japan, of which more later. It must also noted that the restoration effort of an aircraft may involve procedures that are identical to those carried out on the aircraft during its service life due to requirements determined by flight operations and operations related reasons.

\section{REFLECTIONS ON RESTORATION}

What is an authentic aircraft, and what "authentic" components can be accepted for in- stallation in an aircraft under restoration? Discussion should be started by looking at the intended use of the aircraft - which is flying. If it becomes necessary, say, to install an instrument of the same type that was used in the aircraft during its service life, even though it is not the same individual component, authenticity is not sacrificed - only originality is degraded. Following this logic it was decided to install in a Bell P-39Q Airacobra that was undergoing restoration in the Aviation $\mathrm{Mu}$ seum of Central Finland an instrument that was manufactured by the Jaeger company and was exactly of the same type as the instrument previously fitted in the aircraft. It had, however, been used by the Finnish Air Force so the texts on the dial were in Finnish. This resulted in a situation where an instrument with Finnish texts was mounted in an instrument panel adorned with both Russian and English language placards and stenciling in an aircraft of American manufacture. Thus, full authenticity and complete originality were not achieved, yet the result was better than having a gaping hole in the instrument panel, and the decision could also be justified as being an interim measure pending the appearance of a "correct" instrument.

The question of authenticity has been discussed, among other arenas, within the ICOMOS, while an UNESCO meeting held in 1994 in Nara, Japan, eventually agreed that authenticity is not a value in itself, but its task is to convey a message. ${ }^{18}$ The authenticity of different objects may involve different characteristics.

In Japan, on the island of Ise, stands a wooden Shinto shrine, which is rebuilt at twentyyear intervals, and is even slightly relocated on each rebuild. The period of twenty years represents the lifespan of a Shinto goddess to 
whose worship the shrine is dedicated, and after each twenty-year period this object of worship dies and then regenerates. Consideration may also be given to the fact that the Japanese climate with dampness, microbes, fungi, bugs, and other deteriorating factors would in any case necessitate repeated re-erection and relocation of the structure. The current shrine is the 71st iteration to date. Can the shrine be claimed to be authentic even though it is rebuilt every twenty years meticulously adhering to the original method of construction and using original tooling? The Japanese themselves answer in the affirmative. Special attention should be paid to the fact that the work must not be considered merely a repair or maintenance effort as the building of a new shrine is closely tied with a rite that is part of the Shinto religion. ${ }^{19}$

The cathedral of Roskilde in Denmark provides another interesting object when the concept of authenticity is examined. Danish kings of fame have traditionally been buried in side (burial) chapels added up to the cathedral. ${ }^{20}$ Would it still be possible today to erect an additional, perhaps very modern, burial chapel without jeopardizing authenticity? This would represent the continuation of an old tradition, but would architectural differences and differences in construction techniques emerge as decisive factors? If a decision were made to build a replica of a previous chapel, which one of them should be chosen as a pattern?. ${ }^{21}$ What about a traditional Japanese house, then? Its doors, which are made of paper, are replaced once in a year, while the tatami mat is due for replacement after every five years. Thatched roofing is renewed once in a decade, while the wooden poles which support the house must be replaced once or twice in a lifetime. Yet there is little doubt that this building is an aut- hentic Japanese house, in which the rhytmic cycles of human life and seasons regulate structural and other replacements? ${ }^{22}$

D. Wiggins toys with the concept of authenticity and uses the following example: Suppose a wooden ship is constantly undergoing repairs which involve replacement of planking, yet all removed timber is saved. Will it still be the same boat after the replacement of every single plank as it was when it was new? What if the removed planking were used in the construction of another boat using equivalent components and methods - would it then be the same boat, or another? Or, which one of the two would be the more original? Wiggins supports the view that the ship that was under constant repair is the more authentic since it has been subject to long-standing working methods and a continuum, both with regard to time and place. ${ }^{23}$

It can be stated that authenticity has bearing to an object's shape, materials used, (manufacturing) technologies employed, functional originality, and location related originality. Other determinators such as an object's social significance, may also exist. ${ }^{24}$ The Ise shrine and a flying aircraft meet these criteria even though they undergo refurbishment and replacement processes. In the case of an aircraft it must also be realized that some component replacements or repairs may be crucial in view of flight safety and therefore subject to monitoring by authorities. Failing to carry out work laid down in a repair (modification) instruction issued by the manufacturer could result in fatal consequences during flight operations.

Consequently, a museum object must be not only authentic; it should also be original, if this is possible, and it must have connections with its originality, and it must be able to 
106 function as a piece of evidence of events that have taken place in history. ${ }^{25}$ This study has established the links of the two Messerschmitts in the collection of the Aviation $\mathrm{Mu}-$ seum of Central Finland with their past so they can be regarded as pieces of evidence of history. Mooting over the issue of authenticity further, Jukka Jokilehto states that authenticity: "...can be defined as something that sustains and proves itself, as well as having credit and authority from itself." The authenticity of both Messercschmitts that are subject to this study has its roots in the origins of the two objects, it is not water poured into a well. Yet it is generally understood that authenticity and originality are features that in a way increase the merits and authority of an object. When the appreciation of an object is studied over its life span, both high and low points, as well as periods of primary and secondary uses, can be distinguished. To quote Natalia Dushkina: "Authenticity is essential, but change is happening all the time ..." ${ }^{26}$ This is what has happened, particularly over the life span of MT-507. Of the same issue, Janne Vilkuna further states: "Genuine authenticity is often also a paradox. If a museum object is allowed to deteriorate, and eventually become destroyed with the passing of time, it still retains its authenticity throughout this process. If, on the other hand, hard-working conservators and especially restaurers take good care of the object, it becomes less authentic with every single step in restauration." ${ }^{27}$ So we come to conclusion that it is in many ways problematic to define the concept of authenticity and determine the real contents of the term - we can even ask whether there are cases in which this is really needed, or even hoped for? This can even be a manifestation of romantic ideas - to be gen- uinely authentic and original is certainly something very fine indeed, or is it not?

\section{Notes}

1. van Mensch 1990: 146.

2. Kostet 2000: 10; Pearce 1992: 15-17.

3. van Mensch 1992: boek 12: 2-4; Kostet 2000:11-12.

4. Pearce 1992: 192.

5. Pearce 1995: 291.

6. van Mensch 1992: boek 12: 5-6.

7. Radinger \& Schick 1997: 26: "wing slats were considerably simplified", among other changes.

8. Budrass 1998: 679.

9. Prien \& Rodeike 1993: 57. Only six pre-series aircraft were necessary.

10. Mondey 1984: 197-203; [Prescott 2005 (Internet)].

11. The "Remarks" column of the parts catalog for the $\mathrm{Bf} 109 \mathrm{~F}$ version lists all preceding versions in which the component in question can be installed; these include all versions from Bf 109 B up - so a chain of development can be traced. (Messerschmitt AG 1941: passim).

12. Budra? 1998: 568 , footnote 327. Reference is made to a statement given by Director of Aircraft Production Erhard Milch on December 8, 1943. The procedure in question resulted in statistical discrepancies.

13. Droysen 1972: 100.

14. Archives of Aviation Museum of Central Finland, individual aircraft documents, folder of MT-507, inspection record LMT-507 (Werk No. 167271), and a record of release and acceptance confirming the transfer of responsibilityi (No. 2 Air Depot, No. 7520/III/LMT-507, August 26, 1944). The record also details 24 minor deficiencies such as the lack of a tropical filter. This number does not include mentions of equipment 
variations (such as an Erla canopy in lieu of an angular "safe" type canopy, long tailwheel strut, etc.) in the list of baseline equipment.

15. Archives of Aviation Museum of Central Finland, individual aircraft documents, folder of MT-507: the aircraft logged a total of $263 \mathrm{~h} 25 \mathrm{~min}$ in peacetime, which makes up more than $96 \%$ of the total flight hours.

16. Archives of Aviation Museum of Central Finland, individual aircraft documents, folder of MT-452. This example also illustrates the short life of wartime engines as the engines fitted in this particular aircraft averaged no more than 62.5 running hours per engine, so in theory their time between overhauls would have been 100 hours. After a predetermined number of flight hours has elapsed, certain time-expired instruments or other components are replaced with new (or overhauled) items in order to improve flight safety and proactively prevent inflight equipment malfunctions. Manninen 2004: 13, perhaps the most extensive act of cannibalization in Finland was carried out during repairs on MT-449, when the aircraft was fitted with the fuselage of MT-444, among other major components.

17. Archives of Aviation Museum of Central Finland, individual aircraft documents, folder of $\mathrm{OH}$ VKG.

18. Cleere 1995: 254. The chairperson of the meeting Azedine Beschaouch as response.

19. Ito 1995: 40 and 44-45; Inaba 1995: 331.

20. Laenen 1995: 355.

21. Lehmann 2000 (Internet): The current side chapels represent a number of styles: Roman, early Gothic, Dutch renaissance, and classic.

22. Suzuki 1995: 399-400.

23. van Mensch 1992: boek 14: 4.

24. Petzet 1995: 32, 75 and 88; Luxen 1995: 207.

25. Waidacher 1993: 170-171; On the importance of documentation, see, among others, Heinonen \& Lahti 2001: 90-115.
26. Jokilehto 1995: 32 and 74.

\section{ARCHIVES}

Bundesarchiv-Militärarchiv (BA-MA), Freiburg:

Documents on Bf 109 aircraft.

Aircraft losses of flying units 1941 to 1944.

Aircraft status reports 1942 to 1944.

Archives of Aviation Museum of Central Finland,

Tikkakoski:

Jämsen, Osmo: Kunnossapitotekniikka, Korroosio, photocopied text N9518599130, V0068535 of Municipal Library of Turku, dated December 27, 1983. Archives of Raimo Kallio.

Documens of individual aircraft, MT-452, MT507, OH-VKG

Military Archives, Helsinki:

Documents on Messerschmitt Bf 109 aircraft.

\section{ObJects}

Aviation Museum of Central Finland, Tikkakoski: Messerschmitt Bf 109 F-4 aircraft, NE+ML, item \#997 in the collection of the Aviation Museum of Central Finland.

Messerschmitt Bf 109 G-6 aircraft, MT-507, item \#316 in the collection of the Aviation Museum of Central Finland.

Mercedes-Benz DB 605 A-1 aircraft engine, manufacturer's serial \#00201330, item \#297 in the collection of the Aviation Museum of Central Finland.

VDM 9-12159 aircraft propeller, manufacturer's serial \#161.1944, item \#406 in the collection of the Aviation Museum of Central Finland. 
108 INFORMATION COMPILED BY PRIVATE PERSONS

Matti Salonen (manufacturers' serial numbers, dates of manufacture, and numbers produced of versions of the Bf 109 aircraft; acceptance and service data of the Finnish Air Force's Bf 109 aircraft and of Bf 109 F-4, NE+ML).

\section{LITERATURE}

Budrass, Lutz: Flugzeugindustrie und Luftrïstung in Deutschland 1918-1945. Text (50) of Bundesarchiv 50. Dusseldorf 1998, ISBN 3-7700-1604-1.

Cleere, Henry: Session 4, Session Report. Nara Conference on Authenticity in relation to the World Heritage Convention. Paris 1995, ISBN 82-5191416-7.

Droysen, Johann Gustav: Historik. Vorlesungen über Enzyklopädie und Methodologie der Geschichte. Published by Rudolf Hübner. 7th unamended edition. Darmstadt 1972.

Heinonen, Jouko \& Lahti, Markku: Museologian perusteet. Jyväskylä 2001, ISBN 951-9426-25-6.

Inaba, Nobuko: "What is the Test of Authenticity for Intangible Properties?" Nara Conference on Authenticity in relation to the World Heritage Convention. Paris 1995, ISBN 82-519-1416-7.

Ito, Nobuo: "'Authenticity" Inherent in Cultural Heritage in Asia and Japan". Nara Conference on Authenticity in relation to the World Heritage Convention. Paris 1995, ISBN 82-519-1416-7.

Jokilehto, Jukka: "Authenticity: a General Framework for the Concept". Nara Conference on Authenticity in relation to the World Heritage Convention. Paris 1995, ISBN 82-519-1416-7.

Kostet, Juhani: “Mikä on museoesine?" ABOA, Yearbook 61-62/1997-1998 of Regional Museum of Turku. Loimaa 2000, ISBN 951-595-062-7.

Laenen, Mark: "Authenticity in Relation to develop- ment". Nara Conference on Authenticity in relation to the World Heritage Convention. Paris 1995, ISBN 82-519-1416-7.

Luxen, Jean-Louis: Session 3, Session Report. Nara Conference on Authenticity in relation to the World Heritage Convention. Paris 1995, ISBN 82-5191416-7.

Pentti Manninen: Yöhävittäjätoiminta Suomessa 1943-54. Suomen Ilmailuhistoriallinen Lebti 4/2004. Forssa 2004.

van Mensch, Peter: "Methodological museology; or, towards a theory on museum practice". Object of Knowledge. New research in museum studies 1 . (edited by Susan Pearce) Leicester 1990, ISBN 0485-90001-7.

van Mensch, Peter: "Towards a methodology of museology". Museoltowards_a_methodology_of_museologylcontents.htm, museology on CD-ROM, University of Jyväskylä (PhD thesis, University of Zagrebin 1992), printed from the internet on October 27, 2001.

Messerschmitt A.G: Ersatzteil-Liste Bf 109 F, Generalluftzeugmeister Nr. LC 2/V-2854/41/35, April 1941 edition, Augsburg 1941.

Mondey, David: Concise Guide to British Aircraft of World War II. Italy 1984, ISBN 0600349675.

Pearce, Susan: Museums, Objects and Collections: A culturical Study. Leicester 1992, ISBN 07185 13200.

Pearce, Susan: On Collecting, An investigation into collecting in the European tradition. London 1995, ISBN 0415075602.

Petzet, Michael: "In the full richness of their authenticity - The Test of Authenticity and the New Cult of Monuments". Nara Conference on Authenticity in relation to the World Heritage Convention. Paris 1995, ISBN 82-519-1416-7.

Prien, Jochen \& Rodeike, Peter: Messerschmitt Bf 109 F, G, \& K Series, An Illustrated Study. USA 1993, ISBN 0-88740-424-3.

Radinger, Willy \& Schick, Walter: Messerschmitt Me 
109 - Das meistgebaute Jagdflugzeng der Welt, Entwicklung, Erprobung und Technik. Alle Varianten: von $B f(\mathrm{Me}) 109 \mathrm{~A}$ bis $109 \mathrm{E}$. Landshut 1997, ISBN 3-925505-32-6.

Suzuki, Hiroyuki: "Authenticity of Setting in the Cyclical Culture". Nara Conference on Authenticity in relation to the World Heritage Convention. Paris 1995, ISBN 82-519-1416-7.

Waidacher, Friedrich: Handbuch der Allgemeinen $\mathrm{Mu}$ seologie. Vienna 1993, ISBN 3-205-98445-5.

Vilkuna, Janne: Täytetyn tiikerin äärellä-museologia, mitä se on? Finnish Science Academy, Yearbook 2003, Special edition. Jyväskylä 2003, ISBN 951-796-331-9.

\section{INTERNET REFERENCES}

Lehmann, Hans Kr. 2000: http://www.famlehmann.com/katedral-Roskilde.htm. Printed on January 6, 2005.

Prescott, Kelly: Auto History Online, Ferdinand Porsche. http://www.autohistory.org/feature 6.html. Read on October 18, 2005.

*Hannu Valtonen is a retired Lt. Col from the Finnish Air Force and a retired Director of the Aviation Museum of Central Finland. He is the first Finnish PhD of Museology.

Email: hannu.valtonen@kolumbus.fi
Valtonen, Hannu: From Commonplace to Curiosity - The Museum Value of two Messerschmitt Bf 109 - Aircraft at the Central Finland Aviation Museum/TAVALLISESTA KURIOSITEETIKSI - Kahden Keski-Suomen Ilmailumuseon Messerschmitt Bf 109 lentokoneen museoarvo. Jyväskylä: University of Jyväskylä, 2006. Jyväskylä studies in Humanities. ISSN 1459-4323). ISBN 95139-2365-7. 104 pages.

Staff officer Hannu Valtonen's doctoral dissertation in museology "Tavallisesta kuriositeetiksi - Kahden Keski-Suomen ilmailumuseon Messerschmitt Bf 109-lentokoneen museoarvo" (From Commonplace to Curiosity - The Museum Value of two Messerschmitt Bf 109 Aircraft of the Aviation Museum of Central Finland ) is based on three previously published works on Messerschmitt aircraft by the author: 1) Lapin lentokonehylyt. Yli 20 vuotta pohjoista lentokonearkeologiaa (Aircraft Wrecks of Lapland - Over 20 Years of Northern Aircraft Archaeology,1993), 2) Luftwaffen pohjoinen sivusta. Saksan ilmavoimat Suomessa ja Pohjois-Norjassa 1941-1944 (The Northern Flank of the Luftwaffe - German Air Force in Finland and Northern Norway in 1941 1944, from 1997) and 3) Messerschmitt Bf 109 ja Saksan sotatalous (The Messerschmitt Bf 109 and the War Economy in Germany, 1999). The dissertation is the first doctoral thesis in museology to be submitted in Finland, which must naturally be taken into account when evaluating Valtonen's success in this venture and the scholarly significance of the study for museological research. The only comparisons are to be found in studies in ethnology and art history among other subjects, but there is no counterpart to Valtonen's work in material culture studies . 